\title{
Enrichment of Oat Antioxidant Activity by Dry Milling and Sieving
}

\author{
D. A. Gray, R. H. Auerbach, S. Hill, R. Wang*, G. M. Campbell*, \\ C. Webb* and J. B. South† \\ University of Nottingham Division of Food Sciences, Sutton Bonington Campus, Loughborough \\ LE 12 5RD, U.K.; *UMIST Satake Centre for Grain Process Engineering, Manchester \\ M60 1QD, U.K.; †ADAS, Rosemaund Research Centre, Preston Wynne, \\ Hereford HRT 3PG, U.K. \\ Received 18 August 1999
}

\begin{abstract}
Oats contain a range of functional ingredients; these are concentrated to a greater or lesser extent in different parts of the kernel. Dry milling of oats using roller milling offers the opportunity to produce, at a lower processing cost, fractions enriched in antioxidant activity.

Oats were roller milled and the stocks separated by size using sieving; the fractions were analysed for compositional differences. A clear difference was seen between the larger particles, which were richer in bran and its associated components, and the smaller, starch-rich particles, with a natural cut-off point occurring at $420 \mu \mathrm{m}$. This established the feasibility of using dry milling and sieving oats to yield enriched fractions.

Oats (cv. Gerald) from a variety of sources were dehulled then milled once and fractionated to yield a bran-rich fraction $(>420 \mu \mathrm{m})$ and a starch-rich fraction $(<420 \mu \mathrm{m})$. Polar lipid extracts were derived from these fractions and their antioxidant activity measured by chemiluminescence (CL). Bran-rich fractions had significantly higher antioxidant activity than the corresponding starch-rich fraction and appeared to have a more potent population of phenolic antioxidant compounds. (c) 2000 Academic Press
\end{abstract}

Keywords: oats, dry milling, antioxidants, chemiluminescence.

\section{INTRODUCTION}

A range of phenolic compounds with varying solubilities exists in oats. These include ether- or ester-linked glycosides ${ }^{1}$, anthranilic acids and avenanthramides $^{2}$, ester linked glycerol conjugates ${ }^{3,4}$

ABBREviations USED: AACG $=$ American Association of Cereal Chemists, ANOVA = analysis of variance; $\mathrm{BHA}=$ butylated hydroxy anisole; $\mathrm{BHT}=$ butylated hydroxy toluene; $\mathrm{CL}=$ chemiluminescence; $\mathrm{FFA}=$ free fatty acid; $\mathrm{IC}_{50}=$ median inhibitory concentration; $\mathrm{IPA}=$ isopropanol; $\mathrm{PG}=$ propyl gallate; $t \mathrm{BHPO}=$ tertiary-butylhydroperoxide; $\mathrm{TPG}=$ total phenolic content. and ester linked alkyl conjugates ${ }^{5}$. Polar lipid extracts from oats have been obtained which show high levels of antioxidant activity ${ }^{1,6}$. Daniels and Martin $^{5}$ determine the complete chemical structures of phenolic compounds in a polar lipid extract from oats. They identified a range of long chain $\left(\mathrm{C}_{26}\right.$ and $\left.\mathrm{C}_{28}\right)$ mono and diesters of caffeic and ferulic acids. Their antioxidant activity appears to be mediated through their ability to react with free radicals and so break the chain propagation cycle associated with peroxidation reactions.

The use of oat flour to prevent oils becoming rancid was patented as early as the $1930 \mathrm{~s}^{7}$. More recent work ${ }^{8}$ has highlighted the potential of extracted oat antioxidants as a commercially viable source of natural antioxidants for the food in- 
dustry. Since there is serious concern about the toxic and carcinogenic effects of synthetic antioxidants such as butylated hydroxy toluene (BHT), butylated hydroxy anisole (BHA) and propyl gallate $(\mathrm{PG})^{9}$ there is great interest in substituting them with natural antioxidants such as those found in oats ${ }^{10}$.

One problem facing food manufacturers who wish to incorporate natural antioxidants into food formulations is the cost of food safety tests required for a relatively pure extract of natural material. A further problem is the processing costs of producing pure extracts. A solution to both problems could be to incorporate a less refined extract into the formulation. This approach could be limited by the raw material, which may contain other components that adversely affect the quality of the final product.

Cereals may be wet or dry milled. Wet milling allows the separation of relatively pure fractions, while dry milling produces a flour containing a mixture of components. Dry milling is, however, considerably cheaper than wet milling, and the flour produced is appropriate for certain uses. For example, wheat may be wet milled to produce wheat starch and gluten for specialist applications. More commonly, wheat is dry milled into flour, which is of lower value but is appropriate for the production of baked goods. Dry milling may be achieved using hammer mills, which simply break the grain into smaller particles; the composition of the flour is the same as that of the whole grain. In wheat flour milling, this is not adequate, as it is desirable to separate the outer bran layers of the kernel from the inner floury endosperm. For this reason, fluted roller mills are used, as they allow wheat grains to be broken in such a way that the bran particles stay large, while the endosperm particles are smaller. Bran and endosperm can then be separated based on size using plansifters. By using repeated roller milling and sifting, the 'gradual reduction process' used in wheat flour milling achieves highly efficient separation of bran from endosperm.

The use of roller milling technology, adapted from wheat flour milling, offers the opportunity to produce size fractions of oat flour which are enriched in certain fractions, enhancing the functionality of these fractions and their value as food ingredients. Roller milling of oats would be less costly than wet milling, and could produce oat flour fractions more valuable than whole oat flour. However, the higher oil content of oats could potentially prevent the transfer of wheat milling technology to oats.

\section{AIM}

The aim of the work described in this paper is to test the feasibility of producing dry-milled oat fractions with enriched antioxidant activity and bran content, and reduced starch content using roller milling. This work is part of a larger project exploring the potential of dry milling of oats followed by selective dry separations to produce enriched fractions ${ }^{14}$. These fractions could provide a cost-effective route to incorporating functional oat components into food formulations. Firstly, it was necessary to establish the feasibility of dry milling of oats using roller mills. It was then necessary to demonstrate the selective enrichment of functional components such as antioxidant activity, and the reduced content of diluent starch.

\section{MATERIALS AND METHODS}

\section{Materials}

\section{Oat samples}

Oats (Avena sativa), cv. Gerald, were grown in trial plots by ADAS at Rosemaund and Gleadthorpe under a range of agronomic conditions representative of those experienced by commercial crops. Kynon oats, a naked variety also grown by ADAS, were used for preliminary investigations of the effects of operating conditions on milling performance.

\section{Milling and fractionation}

All oat samples (except Kynon) were dehulled using a Streckel \& Schrader laboratory dehuller prior to milling and sieving. Dehulled oat samples $(50 \mathrm{~kg})$ were roller-milled using a single pass in a Satake STR 100 experimental roller mill (UMIST). Careful setting of the mill operating parameters (Table I) enabled the oats to be milled without the anticipated problem of clogging roll flutes.

\section{Reagents}

Tannic acid (code:T/0150/53; batch: 975829347; $\mathrm{C}_{76} \mathrm{H}_{52} \mathrm{O}_{46}$ mol. wt 1701.22) and all solvents (analytical reagent grade) were purchased from Fisher Scientific. Assay kits for $\beta$-glucan determination were purchased from Megazyme, Wicklow, Ireland. All other chemicals were purchased from 
Table I Analytical methods used during milling studies

\begin{tabular}{|c|c|c|}
\hline Component & Method & Condition/Equipment \\
\hline Groat content & Manual dehulling & $10 \mathrm{~g}$ oats \\
\hline Moisture & Dry weight (AACG Method 44-19) & $110^{\circ} \mathrm{C}, 8 \mathrm{~h}$ \\
\hline Ash & Furnacing (AACG Method 08-03) ${ }^{15}$ & $660^{\circ} \mathrm{C}, 6 \mathrm{~h}$ \\
\hline Protein $(\mathrm{N} \times 6 \cdot 25)$ & Nessler's spectrophotometry ${ }^{16}$ & Digesdahl \\
\hline Phosphorus & Molybdovanadophosphoric acid ${ }^{17}$ & Digesdahl \\
\hline Total glucan & Acid hydrolysis ${ }^{18}$ & $\mathrm{pH} 1 \cdot 3,130^{\circ} \mathrm{C}, 20 \mathrm{~min}$ \\
\hline Free lipids & Diethyl ether extraction ${ }^{19}$ & Soxtec system HT6 \\
\hline Total lipids & Diethyl ether extraction $^{19}$ & 3 м $\mathrm{HCl}, 130^{\circ} \mathrm{C} ; 25 \mathrm{~min}$ \\
\hline$\beta$-glucan & AACG method $32-23^{15}$ & \\
\hline Flour acidity & $\mathrm{pH}$ of flour suspension in distilled water & \\
\hline Free fatty acid & Titration (AACC methods 02-01A) ${ }^{15}$ & $1 \mathrm{~g} / \mathrm{L}$ standard $\mathrm{KOH}$ \\
\hline
\end{tabular}

Sigma-Aldrich Chemical Co.; t-butylhydroperoxide $\left(70 \%\right.$ aq. solution), $\mathrm{Na}_{2} \mathrm{~B}_{4} \mathrm{O}_{7} \cdot 10 \mathrm{H}_{2} \mathrm{O}$, luminol (HPLC grade), cytochrome c (horse heart, 99\% pure), silicic acid (100 mesh).

\section{Methods}

\section{Preliminary milling and sieving studies}

The effects of roller mill operating conditions on milling performance of oats were investigated, in terms of the concentration of oat components in milled fractions separated by size. Kynon oats were used for this work, as being a naked variety they did not require dehulling, so were convenient for preliminary studies. (Gerald oats were investigated in the antioxidant studies described below, as these oats were the subject of the agronomic studies carried out within this project and described elsewhere ${ }^{14}$.) The following conditions were varied, using the Satake STR-100 test roller mill: roll gap $(0 \cdot 06,0 \cdot 08,0 \cdot 10,0 \cdot 12,0 \cdot 15 \mathrm{~mm})$ at a differential of 3 relative to a slow roll speed of $200 \mathrm{rev} / \mathrm{min}$; roll differential $(1,1 \cdot 5,2,2 \cdot 5,3,3 \cdot 5$, $5,7 \cdot 5)$ relative to a slow roll speed at a roll gap of $0.08 \mathrm{~mm}$; roll configuration $(10.5$ and 14 flutes per inch); successive millings (one, two and three passes); and effect of heat treatment. Samples of $100 \mathrm{~g}$ were milled and the entire sample collected and separated, to avoid sampling errors. Milled samples were separated on a Simon sifter using 8 inch wire mesh sieves with the following apertures: 2057, 1676, 1204, 850, 600, 420 and $211 \mu \mathrm{m}$, plus a bottom collecting pan $(<211 \mu \mathrm{m})$. The composition of components of oats and of milled and separated fractions were determined using the methods listed in Table I. Based on these trials, the following conditions were chosen as optimal for First Break milling of oats: rolls: 14 flutes per inch, operated sharp-to-sharp; differential: 3; slow roll speed: $200 \mathrm{rev} / \mathrm{min}$; roll gap $0.08 \mathrm{~mm}$; feed rate: $300 \mathrm{~kg} / \mathrm{h}$.

\section{Determination of total glucan ${ }^{18}$}

Total glucan (starch plus $\beta$-glucan) was determined by weighing accurately, $\sim 20 \mathrm{mg}$ of sample into a $20 \mathrm{~mL}$ universal bottle and adding dilute sulphuric acid $(10 \mathrm{~mL})$ at $\mathrm{pH} 1 \cdot 3$. After sealing, the bottle was autoclaved at $130^{\circ} \mathrm{C}$ for $20 \mathrm{~min}$. After cooling to room temperature, a $10 \mu \mathrm{L}$ sample was withdrawn and the glucose concentration determined using a Beckman Glucose Analyser 2 (Beckman, U.S.A.).

\section{Lipid extraction}

Oat flour samples $(100 \mathrm{~g})$ were weighed into a conical flask (2 L) and isopropanol $(1 \cdot 2 \mathrm{~L})$ was added. The flask was then placed into a water bath at $70^{\circ} \mathrm{C}$ and the suspension was stirred with a propeller stirrer at $300 \mathrm{rev} / \mathrm{min}$ for $2 \mathrm{~h}$. To obtain a clear solution the extract was centrifuged at $500 \times \boldsymbol{g}$. The supernatant was rotary evaporated to dryness and dissolved in $7.5 \mathrm{~mL}$ of methanol. Further fractionation was achieved by column chromatography.

\section{Fractionation of the crude lipid extract}

Silicic acid (50 g of $100 \mathrm{mesh}$ ) was activated overnight at $105^{\circ} \mathrm{C}$. It was washed first with three times $100 \mathrm{~mL}$ methanol, then with three times $100 \mathrm{~mL}$ petroleum ether. A petroleum ether slurry of the treated silicic acid was packed into a column $(25 \times 300 \mathrm{~mm})$. The methanolic extract was applied to the top of the column. The first elution was carried out with $300 \mathrm{~mL}$ petroleum ether to 


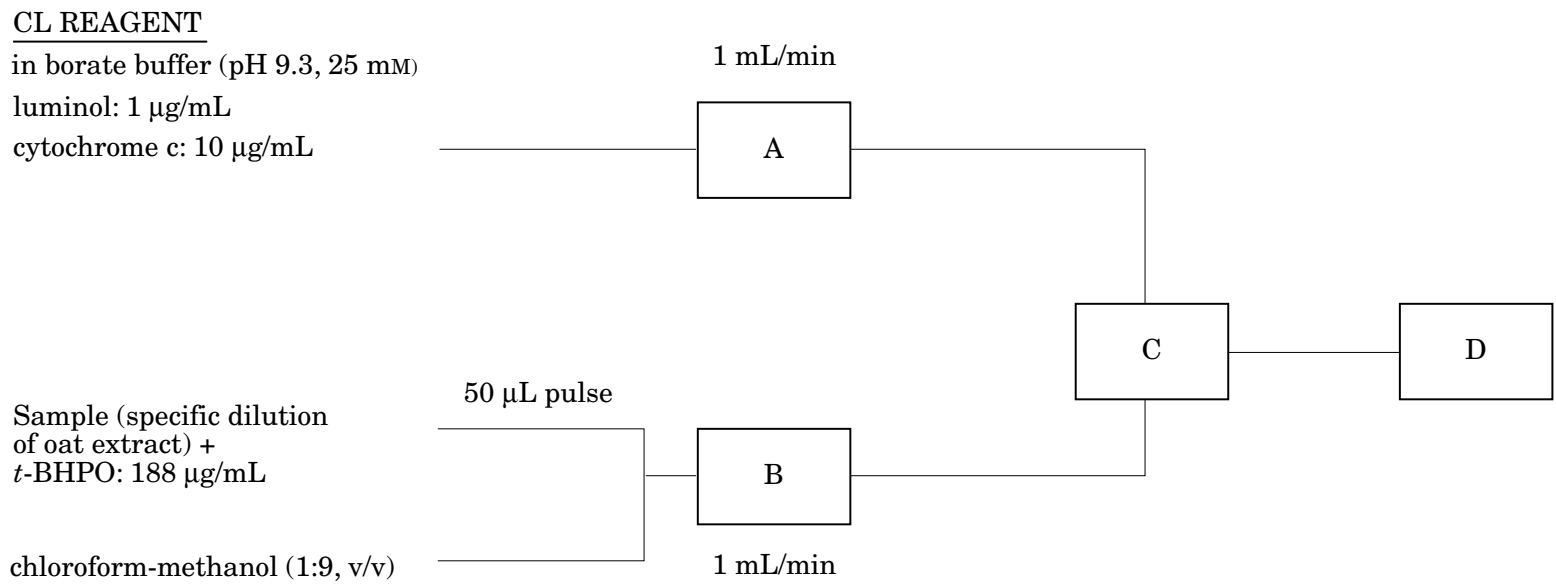

Figure 1 Flow diagram of the chemiluminescence method. A: peristaltic pump (Ismatec sa); B: HPLC pump (Waters 2690); with $50 \mu \mathrm{L}$ injector and sample carousel; C: chemiluminescence detector (JASCO FP-920); D: integrator (Hewlett Packard 3392 A).

extract hydrophobic material and the second with $300 \mathrm{~mL}$ methanol to extract the more polar components. The methanol extract was then rotary evaporated to dryness, dissolved in $7 \cdot 5 \mathrm{~mL}$ methanol, flushed with $\mathrm{N}_{2}$ and stored in the dark at $-80{ }^{\circ} \mathrm{C}$ until further analysis.

\section{Determination of total phenolic content}

The total phenolic content (TPG) was measured following the AOAC Method $(9 \cdot 11)^{20}$, using tannic acid as standard. Samples $(0.4 \mathrm{~mL}$ of extract) were mixed with Folin-Denis reagent and sodium carbonate (at ambient temperature and at the prescribed concentrations) and the absorbance at $760 \mathrm{~nm}$ measured after $30 \mathrm{~min}$.

\section{Measurement of antioxidant activity}

A sensitive and rapid chemiluminescent (CL) method for screening polar lipid extracts from oats for antioxidant activity has been developed ${ }^{21}$. The amount of antioxidant activity in the polar lipid extract was calculated as the median inhibitory concentration $\left(\mathrm{IC}_{50}\right)$. This is the equivalent mass of oats required to decrease (quench) the intensity of chemiluminescence by $50 \%$, hence the greater the activity of the antioxidant the lower the $\mathrm{IC}_{50}$ value.

Instrumentation - The analysis was carried out as depicted in Figure 1. The Waters 2690 pump has an automatic probe sampler and an automatic injector with a sample loop of $50 \mu \mathrm{L}$. Test samples were injected from this loop into the chloroform-methanol mixture and pumped to the CL detector.
Galculation of antioxidant activity-A series of dilutions of the extracts in $7.5 \mathrm{~mL}$ methanol was made using methanol (1:4000, 1:3000 $1: 2000 ; 1: 1500 ; 1: 1000$ and $1: 400)$, and $t$-butyl hydroperoxide was added to a concentration of $3 \mu \mathrm{mol} / \mathrm{mL}$. The peak areas of these dilutions were measured and compared to the area of an equivalent solution minus oat extract, which was set to $100 \%$. The antioxidant activity of each oat extract was calculated as an $\mathrm{IC}_{50}$ (median inhibitory concentration) value, i.e. the concentration of the extract that gives a peak area which is $50 \%$ of the control ${ }^{15}$. The $\mathrm{IC}_{50}$ values are expressed in terms of the equivalent mass of oats which would yield a polar lipid extract that causes $50 \%$ quench in the CL assay.

\section{Data analysis}

Milling studies - Replicate milling trials were not performed; data from single trials were plotted against experimental variables to establish trends, the significance of which were clear from the range of conditions investigated and extent of variation observed. Analyses of ash, phosphorus, $\beta$-glucan, starch, starchy materials, FFA and flour acidity were performed in triplicate, while total lipid, free lipid and protein analyses were performed once for each sample.

Distribution of antioxidant activityDehulled oats were milled and fractionated as described above to yield one starch-rich and one bran-rich fraction per sample. One batch per oat sample was milled, therefore statistical comparison of results between samples is not possible. The 
data analysis therefore concentrates on differences between the fractions within a sample.

All data points were obtained by measuring two separately prepared extracts (duplicates) from the same milled sample. Average and range values for duplicates are quoted in figures and tables. Results from statistical analyses of data (unpaired $t$-tests or ANOVA tests) are discussed in the text.

\section{RESULTS AND DISCUSSION Dry milling process}

Roller milling of wheat is used to separate the floury endosperm material from the outer bran layers. Roller milling tends to keep bran particles large and endosperm particles small, so that they can be separated by size using sifting. The 'gradual reduction process' used by flour millers involves repeated breakage and separation of fractions, resulting in highly efficient recovery of flour, relatively free of bran contamination. Roller mills also tend to give a wide and even particle size distribution, compared with other comminution systems such as hammer or disc mills. This aids the effective separation of flour stocks into compositionally enriched fractions.

Four issues were addressed regarding dry milling of oats: (a) is dry milling applicable to oats?; (b) how rapidly does lipase action occur?; (c) does dry milling of oats give selective concentration of components in different size fractions?; and (d) how does mill operation affect performance?

Oats have the highest oil content among cereals $^{23}$, ranging from $5 \cdot 9-11 \cdot 2 \%$ on a groat (kernel) basis $^{24}$. This high oil content alters their breakage characteristics of the grain, making them more inclined to crush rather than fracture. This could potentially cause difficulties for dry milling; however this did not prove to be the case, and the oat samples were effectively milled in the Satake STR100 test roller mill. The effects of long term operation were not investigated; it is possible that under continuous operation the rolls could become clogged.

A further problem can arise due to lipase activity which can be promoted during the processing of oat grains and results in an increase in the concentration of free fatty acids (FFA). Relative to triacylglycerols, free fatty acids can be rapidly oxidised and give rise to off flavours. This can also affect the antioxidant potential since the free radicals generated during the chain reaction associated with lipid oxidation may be scavenged by associated endogenous antioxidants. This would lower the concentration of active antioxidant molecules in the oat grain and so reduce the yield of antioxidants on extraction. Conventional processing of oats is therefore often preceded by a heating step to inactivate lipases. This was not an option during the current study since heating oat grains may alter their milling properties or change the functionality of some of the components. The rate of FFA production and change of flour acidity was therefore investigated, for both heat treated and untreated flour samples stored in sealed bottles at $30^{\circ} \mathrm{C}$ for several weeks. Kynon oats were heated to $85^{\circ} \mathrm{C}$ in a $110^{\circ} \mathrm{C}$ oven for 15 min, then ground in a Perten Falling Number hammer mill with an $850 \mu \mathrm{m}$ screen. FFA content was measured using AACG Method 02-01A ${ }^{15}$, modified to reduce the flour sample size to $3 \mathrm{~g}$. Due to the high fat-acidity values strong emulsions were formed during titration thus masking the end-point conventionally indicated by phenolphthalein. A pH meter was therefore used to indicate the end-point. Flour acidity was assayed by titrating suspensions in distilled water to $\mathrm{pH} 9$ with $0.0178 \mathrm{~m}$ standard $\mathrm{KOH}$ solution; results are expressed as $\mathrm{mg}$ of $\mathrm{KOH}$ neutralised by one gram of oat flour on a dry basis. Figure 2 shows the free fatty acid (FFA) and flour acidity of heat treated and untreated oat flour samples stored at $30^{\circ} \mathrm{C}$.

The results show that although both free fatty acid production and flour acidity began to increase after milling, the flour did not deteriorate to a significant degree within the time-scale proposed between milling and lipid extraction. For the remainder of this work, antioxidant analyses were performed within $24 \mathrm{~h}$ of milling. Both milling and subsequent analysis were performed at the same time of day to minimise variations in storage time.

Milled stocks were then investigated with regard to the selective separation and concentration of components based on particle size. Figure 3 shows the composition of fractions of Kynon milled under the optimum conditions listed in the Methods, but using rolls of 10.5 instead of 14 flutes per inch. The sieve aperture size indicates the sieve on which the sample was retained. Analyses of the components were performed using the methods summarised in Table I. There is a clear difference in composition of the different size fractions. The coarser fractions were richer in ash and phos- 

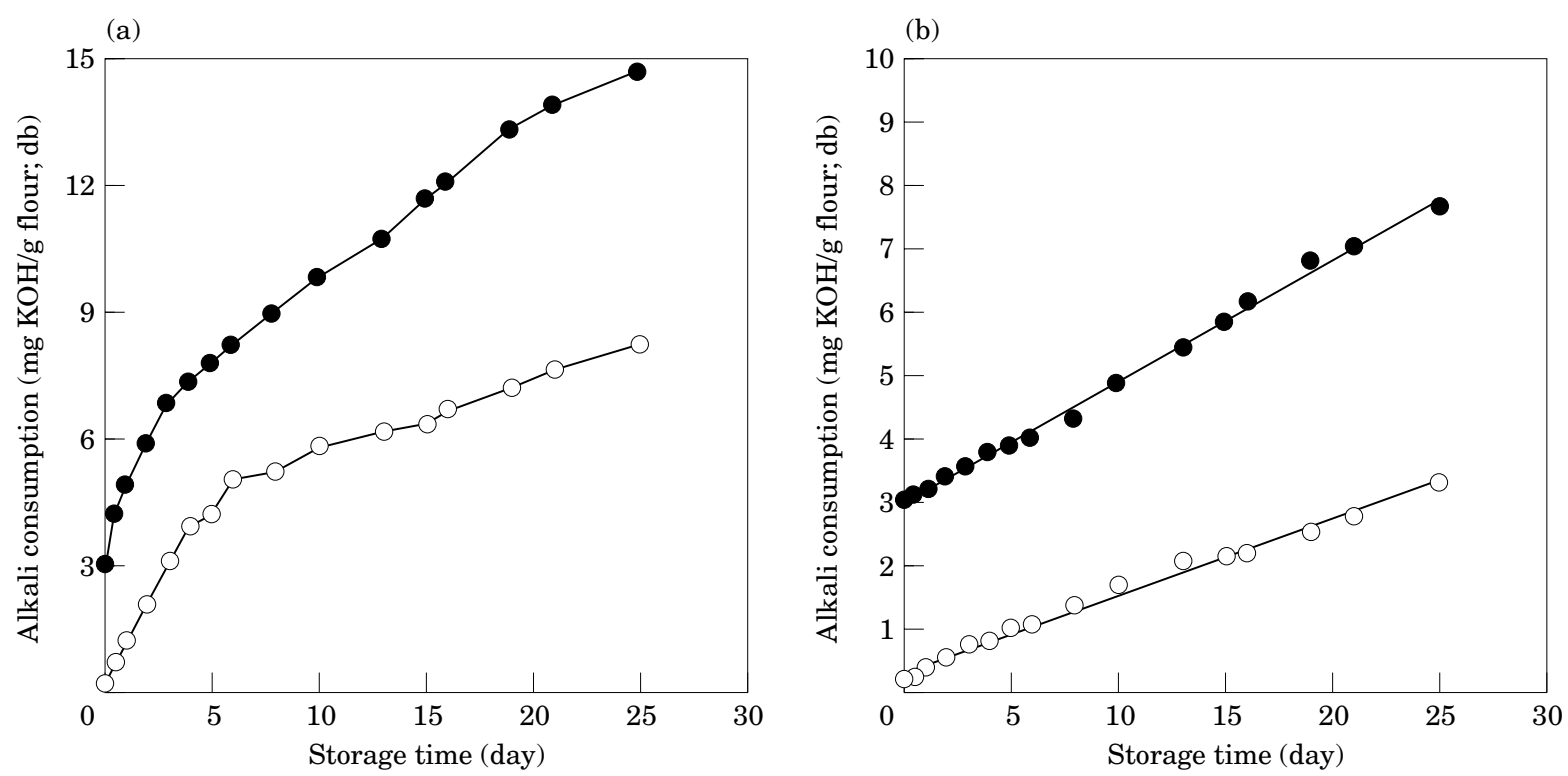

Figure 2 Free fatty acid (FFA) and flour acidity during storage of (a) untreated (open circles: FFA; closed circles: flour acidity), and (b) heat treated Kynon oat flour (open circles: FFA; closed circles: flour acidity; line: regression)
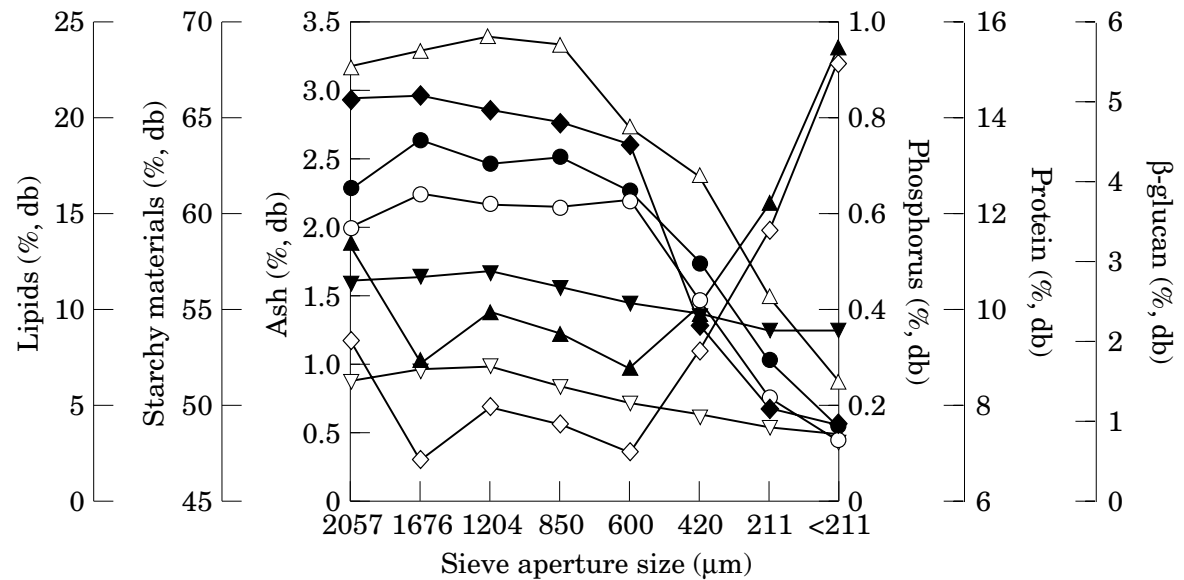

Figure 3 Composition of milled fractions of Kynon oats as a function of sieve aperture size. Roll gap: 0.08 mm; differential: 3; slow roll speed, $200 \mathrm{rev} / \mathrm{min}$, feed rate: $300 \mathrm{~kg} / \mathrm{h}$; fluting: $10 \cdot 5$ flutes per inch.

lipid; - - total glucan; $-\bigcirc-$ phosphorus; $-\triangle$ - protein; $-\nabla$ - free lipid; $-\diamond-$ starch.

phorus (both indicating bran), along with protein and $\beta$-glucan which are associated more with the bran. The smaller fractions had higher contents of starch and total glucan. Figure 3 shows a natural separation into two compositionally different fractions, comprising material smaller than $420 \mu \mathrm{m}$, which was 'starch-rich', and material larger than $420 \mu \mathrm{m}$, which was 'bran-rich'. The coarse branrich fraction contained approximately $15 \%$ protein, $48 \%$ starch and $5 \% \beta$-glucan, while the fine starch-rich fraction contained approximately $9 \%$ protein, $60 \%$ starch and $1 \% \beta$-glucan. Microscope examination of the two flour fractions revealed that the starch-rich fraction was largely derived from the endosperm, whereas the bran-rich fraction was derived mainly from the exterior layers of the grain (pericarp, testa, aleurone and subaleurone endosperm). The proportion of starchrich material separated at $420 \mu \mathrm{m}$ was approximately $30 \%$. Further starch-rich material could be obtained from successive millings and separations; similarly the bran-rich material could 
be further concentrated by additional milling stages.

Figure 3 also shows that the distribution of lipid material (both total and free) was relatively independent of size, indicating that lipids are fairly evenly distributed throughout the oat kernel. However the composition of this lipid material and of functional components within it (e.g. emulsifiers and antioxidants) might well vary between the starch-rich and bran-rich components of the kernel, and might therefore be enriched by this dry milling and separation process.

The effects of roll gap, roll speed differential and fluting on particle size distribution and composition were also investigated. Based on these analyses, a $420 \mu \mathrm{m}$ screen size was chosen as the optimal screen size for producing 'starch-enriched' and 'bran-enriched' flour streams, using the operating conditions set out in Table I. In general, decreasing the roll gap increased the production of the starch-rich fraction, but at the cost of increased bran-contamination. Increasing roll differential increased white flour production but at the cost of increased power requirements. Using rolls with 14 flutes per inch, instead of 10.5 flutes per inch, increased the distinction in composition between the starch-rich and bran-rich fractions and was adopted for the prototype process used to produce samples for subsequent antioxidant analysis.

\section{Recovery of lipids and phenolic compounds by isopropanol (IPA) extraction}

At an absolute level, the quantitative recovery of 'free' lipids using this method $(5-6 \%$ total lipids relative to the total mass of flour) is comparable to amounts quoted in the literature. Furthermore, the proportion of this extract that is composed of polar lipids (as determined gravimetrically after the fractionation step) is between $7-15 \%$. This is less than the values quoted by Forssell ${ }^{25},(14-23 \%)$, who fractionated crude oat oil into neutral and polar fractions using a supercritical fluid extraction method.

The reliability of the IPA lipid extraction and column fractionation method was checked by measuring the TPG values of three different polar lipid extracts obtained from the same oat sample. The following total phenolic content (TPG) values were obtained: $94 \mathrm{mg} / \mathrm{kg} ; 103 \mathrm{mg} / \mathrm{kg}$ and $113 \mathrm{mg} /$ $\mathrm{kg}$. These measurements gave an average of $103 \mathrm{mg} / \mathrm{kg}$ and a standard deviation of $9.5 \mathrm{mg} /$ $\mathrm{kg}$. This recovery of total phenolic compounds in the polar lipid fraction of oats is of the same order of magnitude as values quoted in the literature $(171 \mathrm{mg} / \mathrm{kg}, 30 \mathrm{mg} / \mathrm{kg}, 230 \mathrm{mg} / \mathrm{kg})^{5,26,8}$.

\section{Distribution of antioxidant activity in milled oat fractions}

The distribution of antioxidant activity between the starch-rich and bran-rich fractions was investigated. Polar lipids were quantitatively extracted from these fractions and their antioxidant activity measured (see Table II). Bran-rich fractions were enriched in antioxidant activity (i.e. a lower $\mathrm{IC}_{50}$ value) compared to the starch-rich fraction. Closer analysis of the data using unpaired $t$-tests revealed that these differences were statistically significant $(p<5 \%)$ in all the samples tested.

In an attempt to explain this difference in antioxidant activity between the milled fractions, the total phenolic and lipid contents of each fraction were measured, because (a) the CL method employed relies on the ability of antioxidants to mop up free radicals and such chain blocking antioxidants are predominantly phenolic compounds, and (b) the antioxidant compounds were present in a polar lipid extract.

There was no significant difference between the concentration of total lipid or polar lipid between the two fractions, but a relationship between the total phenolic content (TPC) and antioxidant activity was demonstrated (see Table II). The branrich fractions contained 1 $5-2 \cdot 6$ times more phenolic compounds than the starch-rich fractions. $t$ testing within the oat samples showed differences in TPC values between the starch-rich and branrich fractions (see Table II). The distribution of phenolic compounds between the two fractions, therefore, roughly mirrored the distribution of antioxidant activity ( $\mathrm{IC}_{50}$ values).

$\mathrm{IC}_{50}$ phenolic equivalent values indicate the mass of phenolic compounds in the sample that cause a $50 \%$ quench in the chemiluminescence, calculated from the $\mathrm{IC}_{50}$ and TPG data. If a direct correlation existed between TPC and antioxidant activity then the $\mathrm{IC}_{50}$ phenolic equivalent values between the two fractions would be similar. Clearly this is not the case (see Table II). If one assumes that the decrease in the CL signal is caused primarily by phenolic compounds, then a low $\mathrm{IC}_{50}$ phenolic 
Table II Distribution of antioxidant activity, lipids and ash in milled oat fractions

\begin{tabular}{|c|c|c|c|c|c|c|c|c|}
\hline $\begin{array}{l}\text { Oat } \\
\text { sample }\end{array}$ & $\begin{array}{l}\text { Milled } \\
\text { oat } \\
\text { fraction }\end{array}$ & $\begin{array}{c}\text { Mass }(\% \\
\text { of total) }\end{array}$ & $\begin{array}{c}\text { Ash (\% } \\
\text { fraction } \\
\text { dry } \\
\text { wt.) }\end{array}$ & $\begin{array}{c}\text { Total IPA } \\
\text { extracted } \\
\text { lipid } \\
\text { (mg/kg } \\
\text { fraction) }\end{array}$ & $\begin{array}{c}\text { Polar } \\
\text { lipid } \\
(\% \\
\text { fraction } \\
\text { total } \\
\text { lipid })\end{array}$ & $\begin{array}{c}\text { Total } \\
\text { phenolic } \\
\text { content } \\
\text { (mg/kg } \\
\text { fraction) }\end{array}$ & $\begin{array}{c}\mathrm{IC}_{50} \\
\text { value } \\
(\mathrm{mg} \\
\text { fraction })\end{array}$ & $\begin{array}{c}\mathrm{IC}_{50} \\
\text { phenolic } \\
\text { equivalent } \\
\text { value }(\mathrm{ng})\end{array}$ \\
\hline \multirow[t]{2}{*}{1} & $\mathrm{Starch}^{\mathrm{a}}$ & $63 \cdot 6$ & $0 \cdot 9$ & $53 \cdot 8 \pm 2 \cdot 8$ & $14 \cdot 1$ & $31 \pm 6$ & $1 \cdot 6 \pm 0 \cdot 2^{c}$ & $49 \cdot 1 \pm 2 \cdot 3^{c}$ \\
\hline & Bran $^{\text {b }}$ & $36 \cdot 4$ & $3 \cdot 1$ & $56 \cdot 6 \pm 1 \cdot 0$ & $11 \cdot 0$ & $56 \pm 8^{c}$ & $0 \cdot 5 \pm 0 \cdot 1$ & $27 \cdot 3 \pm 3 \cdot 0$ \\
\hline \multirow[t]{2}{*}{2} & Starch & $63 \cdot 8$ & $0 \cdot 9$ & $48 \cdot 2 \pm 2 \cdot 6$ & $8 \cdot 7$ & 26 & $2 \cdot 5^{\mathrm{c}}$ & $57 \cdot 0$ \\
\hline & Bran & $36 \cdot 2$ & $3 \cdot 0$ & $49 \cdot 7 \pm 3 \cdot 0$ & $7 \cdot 8$ & 68 & $0 \cdot 7$ & $47 \cdot 6$ \\
\hline \multirow[t]{2}{*}{3} & Starch & $51 \cdot 6$ & $0 \cdot 7$ & $47 \cdot 9 \pm 5 \cdot 3$ & $8 \cdot 6$ & 42 & $1 \cdot 6 \pm 0 \cdot 1^{c}$ & 67 \\
\hline & Bran & $48 \cdot 4$ & $2 \cdot 5$ & $55 \cdot 0 \pm 2 \cdot 5$ & $7 \cdot 8$ & 106 & $1 \cdot 0 \pm 0 \cdot 2$ & 106 \\
\hline \multirow[t]{2}{*}{4} & Starch & $51 \cdot 6$ & $0 \cdot 8$ & $51.5 \pm 1.5$ & $11 \cdot 7$ & $62 \pm 2$ & $0 \cdot 5 \pm 0 \cdot 1^{c}$ & $32 \cdot 6 \pm 7 \cdot 0$ \\
\hline & Bran & $48 \cdot 4$ & $2 \cdot 6$ & $56 \cdot 8 \pm 1 \cdot 8$ & $13 \cdot 2$ & $94 \pm 3^{c}$ & $0 \cdot 3 \pm 0 \cdot 1$ & $27 \cdot 6 \pm 11 \cdot 2$ \\
\hline \multirow[t]{2}{*}{5} & Starch & $46 \cdot 8$ & $0 \cdot 7$ & $51 \cdot 5 \pm 1 \cdot 2$ & $11 \cdot 8$ & $46 \pm 5$ & $2 \cdot 2 \pm 0 \cdot 1^{\mathrm{c}}$ & $99.6 \pm 13.9^{\circ}$ \\
\hline & Bran & $53 \cdot 2$ & $2 \cdot 4$ & $57 \cdot 3 \pm 2 \cdot 4$ & $12 \cdot 0$ & $86 \pm 1^{\mathrm{c}}$ & $0 \cdot 6 \pm 0 \cdot 1$ & $49 \cdot 1 \pm 7 \cdot 0$ \\
\hline \multirow[t]{2}{*}{6} & Starch & $53 \cdot 2$ & $0 \cdot 8$ & $46 \cdot 7 \pm 0 \cdot 9$ & $8 \cdot 6$ & $53 \pm 3$ & $1 \cdot 4 \pm 0 \cdot 1^{\mathrm{c}}$ & $72 \cdot 6 \pm 8 \cdot 1^{\mathrm{c}}$ \\
\hline & Bran & $46 \cdot 8$ & $2 \cdot 5$ & $55 \cdot 8 \pm 1 \cdot 7$ & $9 \cdot 9$ & $84 \pm 5^{\mathrm{d}}$ & $0 \cdot 4 \pm 0 \cdot 0$ & $33 \cdot 4 \pm 1 \cdot 8$ \\
\hline
\end{tabular}

${ }^{\mathrm{a}}$ One batch from each of six oat sample was dry-milled and fractionated into starch(starch-rich); ${ }^{\mathrm{b}}$ bran (bran-rich) fractions. Their relative mass was recorded and the percentage of ash present in each fraction measured. Ash is a good indirect measurement of bran content and shows a clear enrichment in the branrich fraction. Duplicate isopropanol extracts were separated into polar lipid fractions and their antioxidant activity measured by chemiluminescence (average values \pm the range of duplicate extracts are shown). $t$-testing within oat samples; ${ }^{c}$ statistically greater value $(p<5 \%)$ than the corresponding milled fraction; ${ }^{\mathrm{d}}$ statistically greater value $(p<10 \%)$ than the corresponding milled fraction.

equivalent value would indicate that a population of active phenolic compounds exists; if a relatively higher value is calculated a population of less active phenolic compounds exists. The latter situation may result from the dilution of active phenolics with a relatively high concentration of phenolic compounds with reduced antioxidant activity, or alternatively it could be explained by the loss of synergistic phenolic compounds from the overall population of phenolic compounds. Branrich fractions from all samples tested, with the exception of sample 3 , had lower $\mathrm{IC}_{50}$ phenolic equivalent values than the equivalent starch-rich fractions (see Table II).

These results, therefore, strongly suggest that the bran-rich fraction from the majority of samples tested contains a more powerful antioxidant mixture of phenolic compounds than the starch-rich fraction. Interestingly, in one of the few studies that addresses the total antioxidant activity of a bran fraction, Onyeneho and Hettiarachchy ${ }^{27}$ produced indirect evidence of strong synergistic interactions between durum wheat bran phenolic compounds when added to heat-stressed soya oil. It is possible, however, that some non-phenolic synergists or antioxidant compounds are present in our bran-rich fraction, or conversely that the starch-rich fractions contains a non-phenolic inhibitor of chain-blocking antioxidant activity.

\section{CONCLUSIONS}

The evaluation of dry milling technology for oats, adapted from wheat flour milling shows that dry milling offers the opportunity to produce enriched fractions at low cost using existing roller milling equipment. The dry milling and fractionation procedure developed in the initial stages of this work yielded bran-rich and starch-rich fractions. Within the time-scale between dehulling, milling and lipid extraction, flour quality did not significantly deteriorate due to lipase activity. Most importantly dehulling of oats followed by prolonged storage of several weeks at ambient temperature did not result in any loss of antioxidant activity (data not shown).

Antioxidant activity was enriched by between 60 and 257\% (on an activity per unit mass of flour basis) in the bran-rich fraction compared to the starch-rich fraction, depending on the oat sample analysed. True differences in antioxidant activity relative to total phenolic content were found when comparing bran-rich with starch-rich fractions. 
Whether this effect is due to the actual distribution of phenolic compounds or of antioxidant inhibitors/promoters in vivo is not known and requires further research. One may however reasonably speculate that the separation of phenolic compounds by milling could be selective, resulting in distinct populations in the starch and bran-rich fractions. These populations may contain phenolic compounds with enhanced synergistic antioxidant activity, which causes a decrease in the $\mathrm{IC}_{50}$ value.

The bran-rich fraction, which contains significant sub-aleurone endosperm, still contains approximately $48 \%$ starch compared to $60 \%$ starch in the starch-rich fraction; purification of the branrich fraction by further milling steps may therefore be possible to reduce starch content. Whether this approach would result in a further enhancement of antioxidant activity, and in an oat preparation with real commercial potential, remains to be demonstrated.

\section{Acknowledgements}

The authors wish to thank the Home Grown Cereal Authority (HGCA) for their sponsorship of this work. The Satake Corporation of Japan is gratefully acknowledged for its support of the Satake Centre for Grain Process Engineering.

\section{REFERENCES}

1. Collins, F.W. Oat phenolics: Structure, occurrence and function. In 'Oats: Chemistry and Technology', (F.H.Webster, ed.), American Association of Cereal Chemists, St. Paul, MN (1986) 227-295.

2. Dimberg, L.H., Theander, O. and Lingnert, H. Avenanthramides: A group of phenolic antioxidants in oats. Cereal Chemistry 70 (1993) 637-641.

3. Taketa, F.J. Studies of various nutritional factors in relation to dental caries in the rat. Ph.D. thesis, University of Wisconsin, Madison (1957).

4. Vogel, J.J. Studies on the diet in relation to dental caries in the cooton rat. Ph.D. thesis, University of Wisconsin, Madison (1961).

5. Daniels, D.G. and Martin, H.F. Antioxidants in oats: mono-esters of caffeic and ferulic acids. Fournal of the Science of Food and Agriculture 18 (1967) 589-595.

6. White, P.J. Novel natural antioxidants and polymerisation inhibitors in oats. In 'Natural Protectants against Natural Toxicants', (W.R.Bidlack and S.T.Omaye, eds), Technomic Publishing Company, Lancaster, Pennsylvania U.S.A. (1995) 35-49.

7. Musher, S. Oil with grain material to stabilise against oxidation. United States Patent 2,049,017 (1936).

8. Xing, Y. and White, P.J. Identification and function of antioxidants from oat groats and hulls. Fournal of the American Oil Chemists Society 74(3) (1997) 303-307.

9. Branen, A.L. Toxicology and biochemistry of butylated hydroxyanisole and butylated hydroxytoluene. Fournal of the American Oil Chemists Society 52 (1975) 59-63.

10. Pratt, D.E. Natural antioxidants from plant material. In 'Phenolic Compounds in Food and their Effects on Health' Abstracts of Papers of the American Chemical Society vol. 202 (1992) 15.

11. Anderson, J.W. and Bridges, S.R. Hypocholesterolemic effects of oat bran in humans. In 'Oat Bran', (P.J.Wood, ed.), American Association of Cereal Chemists, MN, U.S.A. (1993) 139-157.

12. Wood, P.J. Functional foods for health: Opportunities for novel cereal processes and products. In 'Cereals: Novel Uses and Processes', (G.M.Campbell, C.Webb and S.L.McKee, eds), Plenum Press, New york, U.S.A. (1997) 233-239.

13. Posner, E.S. and Hibbs, A.N.Wheat Flour Milling, American Association of Cereal Chemists, St. Paul, Minnesota, U.S.A. (1997).

14. South,J.B., Townsley, C., Atkin, D., Alvey, M., Laverick, R.M., Webb, C., Campbell, G., Wang, R., Gray, D.A., Hill, S., Auerbach, R., Jumel, C., Barclay, F., Sriburi, P., Forge, C., Rogers, L., Kelly, L., Livermore, M., Smith, I. and Jee, M. Sourcing added value food ingredients from home-grown oats. HGCA Project Report No. 194, (1999).

15. Approved methods of the American Association of Cereal Chemists, 9th Edition. American Association of Cereal Chemists Inc., MN, U.S.A. (1995).

16. HACH Water Analysis Handbook, 2nd edition. Loveland, Colorado, U.S.A. (1992).

17. Kitson, R.E. and Mellon, M.G. Colorimetric determination of phosphorus as molybdovanadophosphoric acid. Ind. Eng. Chem. 16 (1944) 379-383.

18. Wang, R. Continuous production of a generic fermentation feedstock from whole wheat flour. Ph.D. thesis UMIST, Manchester, U.K. (1999).

19. Molteberg, E.L., Vogt, G., Nilsson, A. and Frolich, W. Effects of storage and heat processing on the content and composition of free fatty acids in oats. Cereal Chemistry $\mathbf{7 2}$ (1995) 88-93.

20. AOAC Official Methods of the Analytical Chemists. Association of the Official Analytical Chemists. Washington, D.C. (1984).

21. Auerbach, R.H. and Gray, D.A. Oat antioxidant extraction and measurement - towards a commercial process. Fournal of the Science of Food of Agriculture 79 (1999) 385-389.

22. Ashida, S., Okazaki, S., Tsuzuki, W. and Suzuki, T. Chemiluminescence method for the evaluation of antioxidant activity using lipid hydroperoxide-luminol. Analytical Sciences 7 (1991) 93-96.

23. McMullen, M.S. Oats. In 'Handbook of Cereal Science and Technology', (K.J.Lorenz and K.Kulp, eds), Marcel Dekker Inc., New York, U.S.A. (1991) 199-232.

24. Youngs, V.L. Oat lipids and lipid-related enzymes. In 'Oats: Chemistry and Technology', (F.H.Webster, ed.), American Association of Cereal Chemists, St. Paul, MN, U.S.A. (1986) 205-226.

25. Forssell, P., Kervinen, R., Alkio, M. and Poutanen, K. Comparison of methods for separating polar lipids from oat oil. Fat Science and Technology 9 (1992) 355-358. 
26. Tian, L.L. and White, P.J. Antioxidant activity of oat in soybean and cottonseed oils. Fournal of the American Oil Chemists Society 71(10) (1994) 1079-1086.
27. Onyeneho, S.N. and Hettiarachchy, N.S. Antioxidant activity of durum wheat bran. Fournal of the Agricultural and Food Chemistry 40 (1992) 1496-1500. 